\title{
An assessment of the Jenkinson and Collison synoptic classification to a continental mid-latitude location
}

\author{
Greg Spellman ${ }^{1}$
}

Received: 16 June 2015 / Accepted: 16 December 2015 /Published online: 28 January 2016

(C) The Author(s) 2016. This article is published with open access at Springerlink.com

\begin{abstract}
A weather-type catalogue based on the Jenkinson and Collison method was developed for an area in south-west Russia for the period 1961-2010. Gridded sea level pressure data was obtained from the National Centers for Environmental Prediction/National Center for Atmospheric Research (NCEP/NCAR) reanalysis. The resulting catalogue was analysed for frequency of individual types and groups of weather types to characterise long-term atmospheric circulation in this region. Overall, the most frequent type is anticyclonic (A) (23.3\%) followed by cyclonic (C) (11.9\%); however, there are some key seasonal patterns with westerly circulation being significantly more common in winter than summer. The utility of this synoptic classification is evaluated by modelling daily rainfall amounts. A low level of error is found using a simple model based on the prevailing weather type. Finally, characteristics of the circulation classification are compared to those for the original JC British Isles catalogue and a much more equal distribution of flow types is seen in the former classification.
\end{abstract}

\section{Introduction}

Techniques in synoptic climatology have long been effective in the classification of atmospheric circulation patterns (or weather types) at a variety of locations. One of the aims is to relate large-scale circulation variability to temperature and precipitation variability at point scales and therefore

Greg Spellman

greg.spellman@northampton.ac.uk

1 School of Science and Technology, University of Northampton, Northampton NN2 6JD, UK downscale the surface pressure field output of general circulation models (Jones et al. 2013). Results can then be used to bias adjust the temperature and precipitation output of climate models. Synoptic classifications have been created using a number of techniques ranging from simple subjective pattern identification of the surface pressure field, for instance Lamb weather types (LWTs) (Lamb 1972), to catalogues based on multivariate statistical analysis (Yarnal 1993). The objective method of Jenkinson and Collison (1977) (JC), which replaced the LWT system, was originally developed for the British Isles region; however, Jones et al. (2013) comment that the JC method can be applied to any mid-to-highlatitude region $\left(\sim 30^{\circ}-70^{\circ}\right)$. Indeed, several applications can be found in the literature, for example, for the Netherlands (Buishand and Brandsma 1997), Portugal (Trigo and DaCamara 2000), Sweden (Chen 2000), Spain (Spellman 2000), Estonia (Post et al. 2002), Chile (Espinoza et al. 2014) and the Western Mediterranean (Grimalt et al. 2013). All of these authors have investigated mid-latitude maritime regions with a significant proportion of open water upwind. In fact, many other synoptic classifications have also focused on locations in coastal regions such as Norway (Fitzharris and Bakkehøi 1986) and New Zealand (Kidson 1994). Less assessment of the value of synoptic climatological approaches has been undertaken deep within continental areas, although Petrone and Rouse (2000) and Spence and Rausch (2005) employed the use of a weather-type classification to explain precipitation patterns in Central Canada and a number of studies have been undertaken in Iran by Alijani and Harman (1985) and Jahanbakhsh and Zolfaghari (2002).

The study area is situated in Russia north of western Kazakhstan roughly within a rectangular grid with northwest coordinates of $60^{\circ} \mathrm{N}, 50^{\circ} \mathrm{E}$, and south-east coordinates of $50^{\circ} \mathrm{N}, 60^{\circ} \mathrm{E}$ (Fig. 1). It includes the republics of Bashkortostan and Tatarstan and the cities of Samara and 
Fig. 1 Location of the study area (points identify the locations of meteorological stations used in this study)

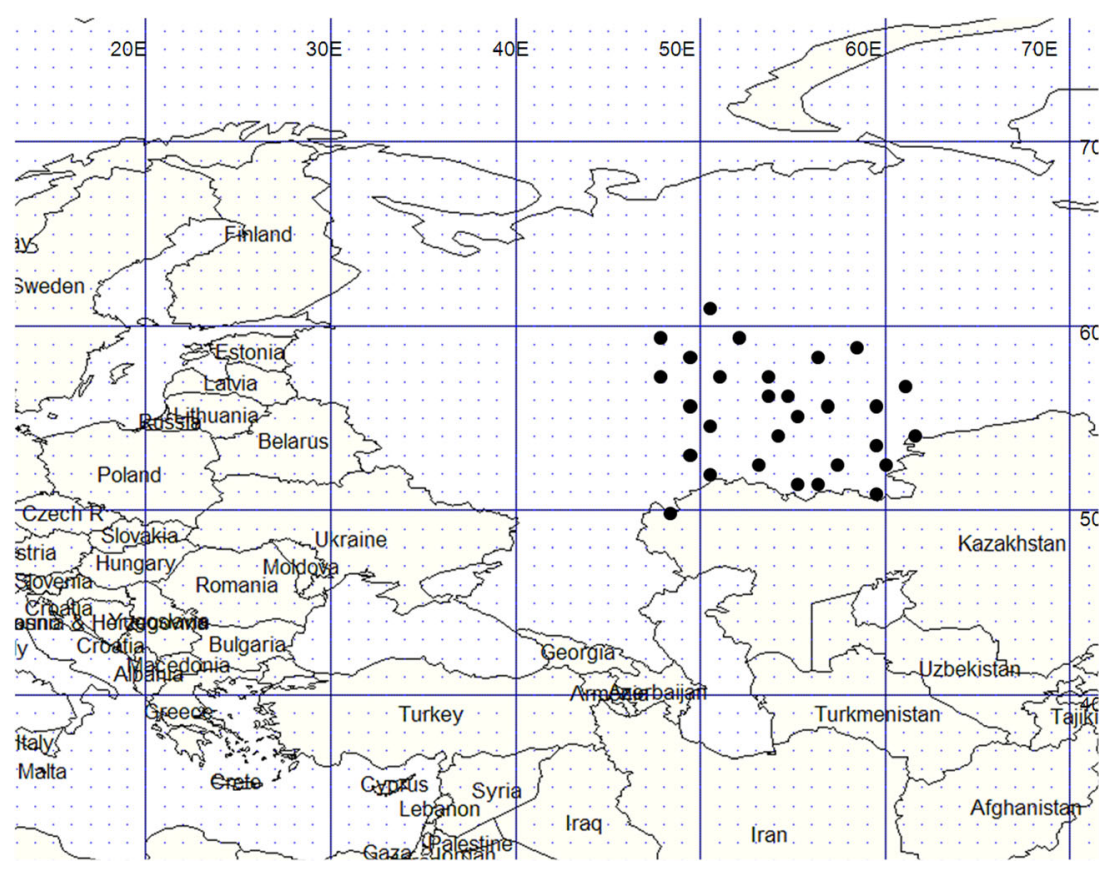

Perm. Topography slowly rises from low-altitude plains in the west to the southern Urals in the east $(<600 \mathrm{~m})$, although altitude rarely rises above $300 \mathrm{~m}$. The northern coasts of the Caspian Sea and the Black Sea (the only significant sources of surface moisture) lie 1000 and $1500 \mathrm{~km}$, respectively, from the centre of the study area. According to the Köppen-Geiger climate classification, it is defined as the Dfb (humid continental) climatic type (Barry and Chorley 2009). Thermally, this type is characterised by large seasonal temperature differences with warm to hot summers and cold (sometimes severely cold) winters. Most Dfb types exhibit rainfall that is well distributed throughout the year, although some areas have a seasonal rainfall regime of dry winters and a peak of largely convective rainfall in early summer. The humid designation of this type does not mean that the humidity levels are necessarily high, only that the climate is not dry enough to be classified as semi-arid or arid.

The purpose of the current study was to develop a weather typing scheme for an area of south-west Russia using the Jenkinson and Collison method. A daily catalogue of surface circulation was created for a 50-year period from 1961 to 2010. This extensive record permits the investigation of the key modes of variability of atmospheric circulation, and the main features of this catalogue can be compared to other locations at the same latitude but in a different longitudinal sector and hence subject to different long-term circulation patterns. The maritime JC catalogue for the British Isles (JCBI) provides a good contrast to this continental classification. Finally, the catalogue was used to determine the extent to which daily precipitation amount is controlled by the weather type in this area and, subsequently, to evaluate if this relationship is strong enough to form the basis of a predictive model of mean station rainfall.

\section{Data and methodology}

Gridded daily mean sea level pressure data for $12 \mathrm{~h}$ UTC was obtained from the National Centers for Environmental Prediction/National Center for Atmospheric Research (NCEP/NCAR) project. The NCEP Reanalyses (Kalnay et al. 1996) are available at the relatively high spatial resolution ( $2.5^{\circ}$ by $2.5^{\circ}$ latitude/longitude) that provides the necessary data for the JC method grid. The latitude/longitude resolution used here is extracted for the 16-point grid shown in Fig. 2 so the computed variables represent surface airflow for this region. The JC method classifies daily map patterns using three basic variables that define circulation features over the study area: the direction of mean flow $(D)$, the strength of mean flow $(F)$ and the vorticity $(Z)$. A set of daily index values are calculated using the equations in Appendix 1 and identify the following flow features:

$W \quad$ The zonal component of geostrophic (surface) wind, calculated as the pressure gradient between $45^{\circ} \mathrm{N}$ and $65^{\circ} \mathrm{N}$

$S \quad$ The meridional component of geostrophic (surface) wind, calculated as the pressure gradient between $40^{\circ}$ $\mathrm{W}$ and $70^{\circ} \mathrm{W}$

$D \quad$ The wind direction (azimuth degree) derived from $S$ and $W$ above

$F \quad$ The wind speed $\left(\mathrm{ms}^{-1}\right)$ 
$Z W \quad$ The zonal vorticity component

$Z S \quad$ The meridional vorticity component

$Z \quad$ The total vorticity derived from $Z W$ and $Z S$.

The JC method was devised to capture objectively the 27 atmospheric circulation patterns that exist in the Lamb weather type system. Jones et al. (1993) showed how the objective method was effective in replicating the LWT classes. LWTs comprise eight pure advective (or directional) types based on wind direction (e.g. SE or southeast); A and C types which represent anticyclonic and cyclonic pressure patterns, respectively, but no coherent flow direction; and 16 hybrid types that represent directional types with either anticyclonic isobaric curvature (e.g. AN or anticyclonic northerly) or cyclonic curvature (e.g. CSE or cyclonic southeasterly). The final type undetermined $(\mathrm{U})$ represents patterns that have weak pressure gradients, and thus, neither flow direction nor vorticity can be identified. Examples of some of the more frequent types in the catalogue are shown in Fig. 3.

\section{Results: atmospheric circulation catalogue}

Eighteen thousand two hundred sixty-two days were classified according to the JC classification (Table 1). In the resultant catalogue for south-west Russia (hereafter termed 'JCSWR'), there is a considerable variability in surface circulation without domination by any individual weather type. This is typical of mid-latitude atmospheric circulation. It contrasts with the lower-latitude Mediterranean region where Grimalt et al. (2013) found that three types alone (U, A and C) account for $68 \%$ of all days. They reported a $27 \%$ mean occurrence of undetermined flow (the most frequent type) in their annual catalogue. These are termed 'barometric swamps' (Jorba et al. 2004) and are a key feature of summer circulation in the Mediterranean area. In contrast, U types only constitute $4.46 \%$ of all days in JCSWR; however, there is a notable rise in June (9\%) and July (10\%). The most frequent type is A with an annual average of 85 days (23.3\%). It is followed by $\mathrm{C}$ (43.6 days, $11.9 \%$ ) and then $\mathrm{W}$ (26.6 days, $7.3 \%$ ). The two most frequent types record annual maxima of 132 days (A) and 62 days (C). Hybrid types are unusual and, in some instances, do not even occur at all in any one year. CS, for example, which features on only 96 days in the entire 50-year period, is absent in 10 of these years and only reaches a maximum occurrence of 5 in 2006. None of the hybrid types are recorded more than 25 times in any year. Seasonal differences can be seen in type occurrence with westerly component types (e.g. W, ANW, $\mathrm{CW}$ ) being significantly more frequent in winter and those with north and easterly components occurring more often in the summer months.

Simple analysis of the 2-day persistence of each weather type reveals that the probability of an A type being followed by another A type is 0.531 which is considerably greater than that associated with a 2-day spell of the next most persistent weather type SE (0.313). Directional types tend to persist longer than any of the hybrid types with infrequent cyclonic types such as CSW being the most transitional (0.049). The A types regularly persist for 7 days or more, the longest run being 18 days in September/October 1974.

In their analysis of a weather typing in the Western Mediterranean, Grimalt et al. (2013) facilitated the description of atmospheric circulation by examining groups of weather
Fig. 2 The 16-point grid used to calculate the circulation index values

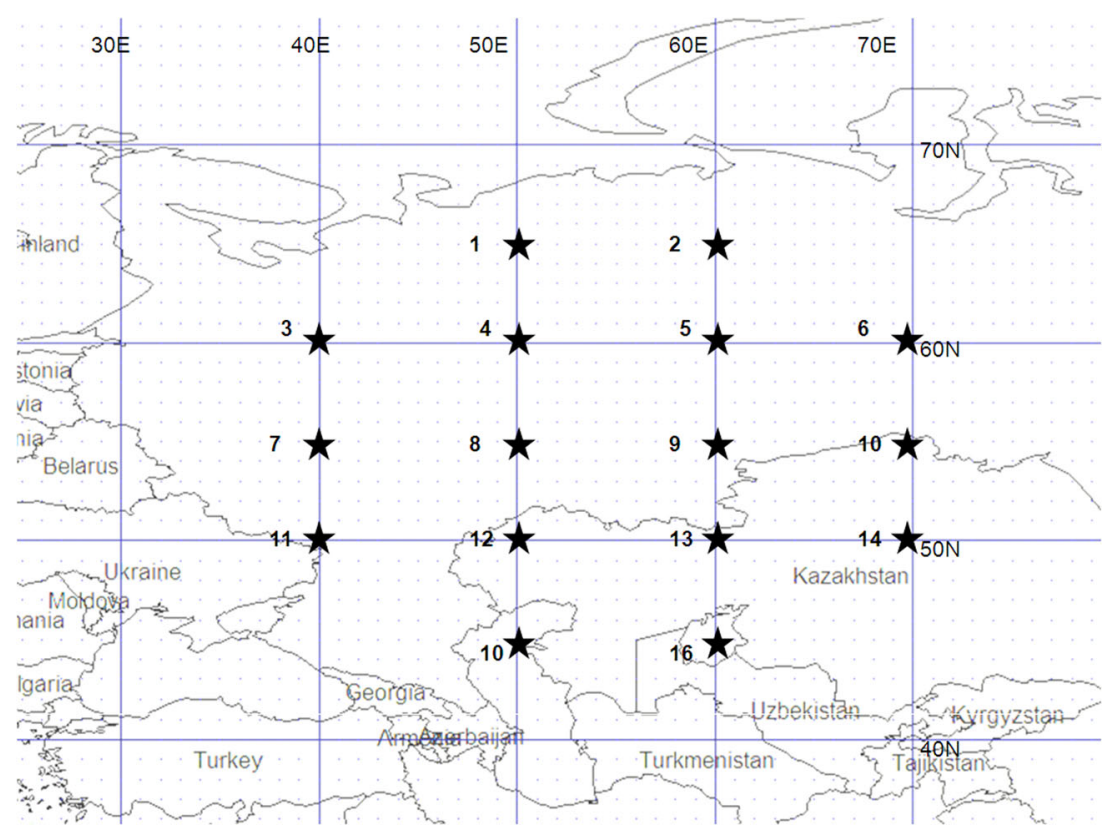


Fig. 3 Typical examples of main weather types

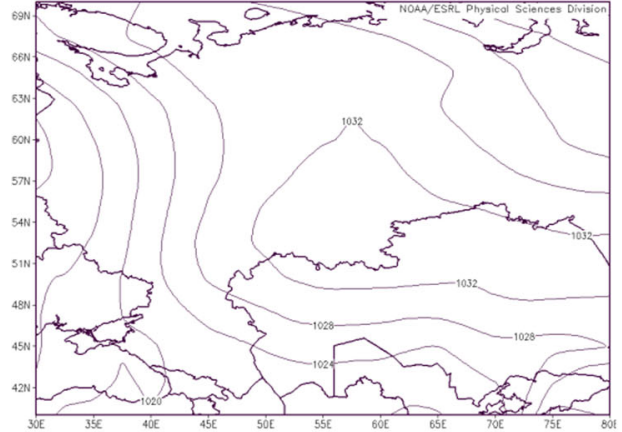

A - 29 November 1996

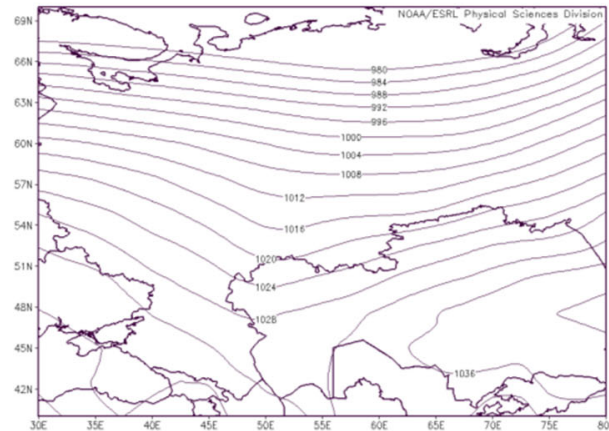

W- 29 January 1989

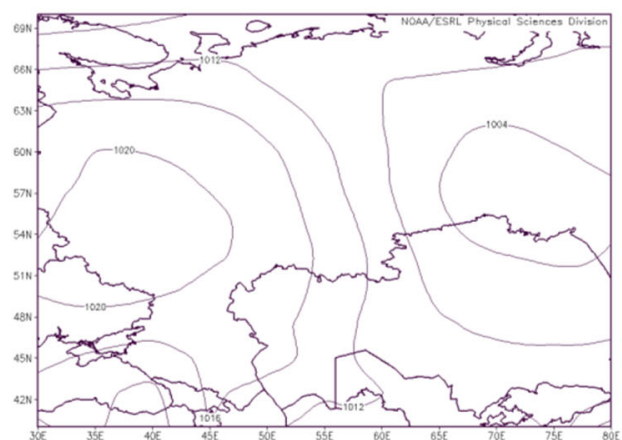

N-1 July 2001

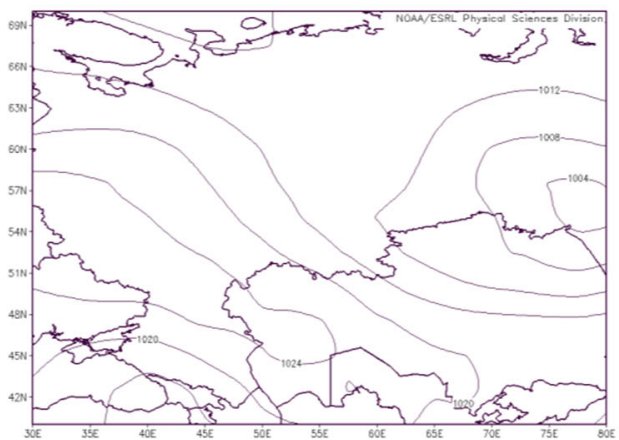

NW-19 September 1970

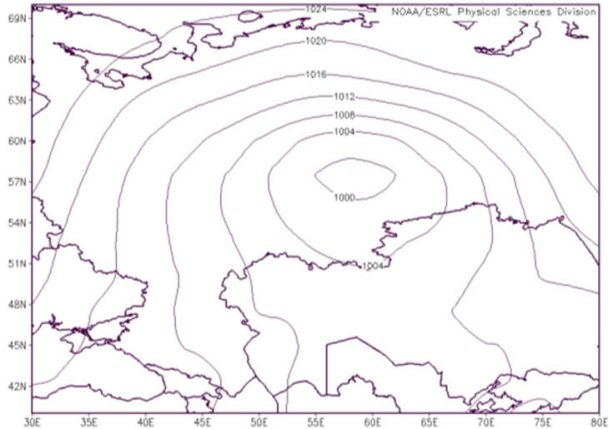

C- 9 November 1999

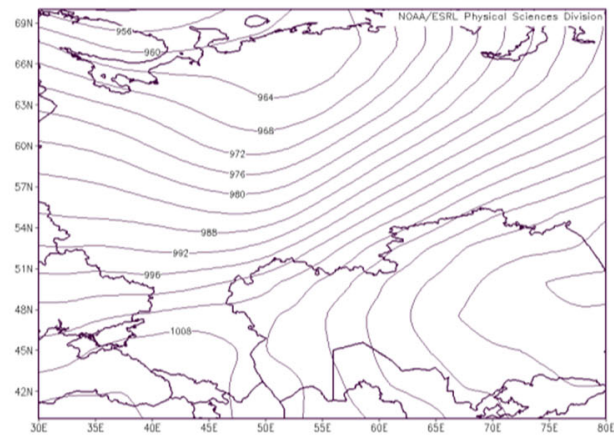

SW-2 August 1995

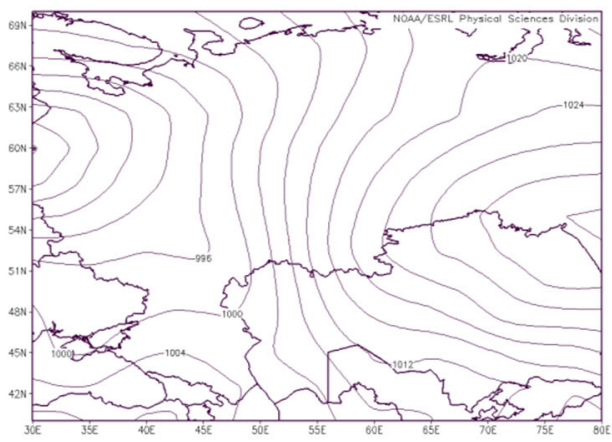

S - 26 March 2008

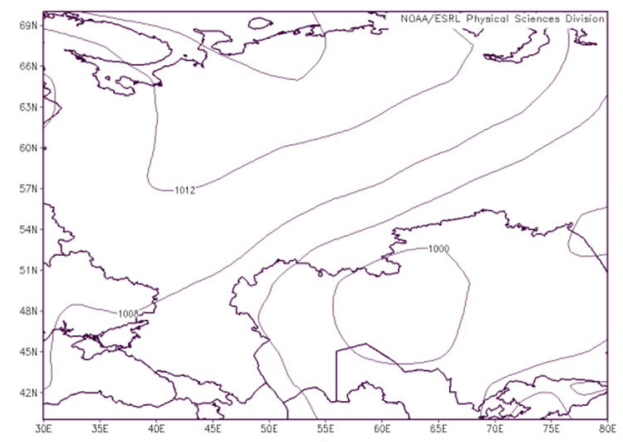

NE - 19 July 2001 types based on vorticity and directional characteristics. Grouping is also undertaken by Espinoza et al. (2014) for their catalogue of weather types in Central Chile. In this research, two sets of groups are identified (Table 2).
Set 1 In this set, three groups assess the overall strength of vorticity over the region: (i) negative termed 'anticyclonic' or 'ANT' (A, AN, ANE, AE, ASE, AS, ASW, AW, ANW), (ii) positive vorticity termed 'cyclonic' or 'CYC' $(\mathrm{C}, \mathrm{CN}, \mathrm{CNE}$, 
Table 1 Total number of days, annual mean and percentage, annual maximum and minimum and coefficient of variation (CV) of the JC classification types

\begin{tabular}{|c|c|c|c|c|c|c|c|c|}
\hline JC type & Days & Mean & Percent & Max & Min & $\mathrm{CV}$ & Summer $\%$ & Winter \% \\
\hline $\mathrm{N}$ & 705 & 14.1 & 3.86 & 25 & 6 & 33.79 & 5.34 & 2.37 \\
\hline $\mathrm{NE}$ & 465 & 9.30 & 2.55 & 18 & 3 & 41.91 & 4.00 & 1.09 \\
\hline $\mathrm{E}$ & 367 & 7.34 & 2.01 & 22 & 1 & 58.04 & 2.62 & 1.39 \\
\hline SE & 601 & 12.02 & 3.29 & 22 & 3 & 35.48 & 3.70 & 2.88 \\
\hline S & 653 & 13.06 & 3.58 & 26 & 3 & 34.22 & 3.10 & 4.05 \\
\hline SW & 1407 & 28.14 & 7.70 & 42 & 12 & 25.50 & 4.28 & 9.89 \\
\hline W & 1332 & 26.60 & 7.29 & 46 & 12 & 29.82 & 4.71 & 5.08 \\
\hline NW & 977 & 19.54 & 5.35 & 30 & 7 & 27.55 & 5.62 & 5.08 \\
\hline $\mathrm{C}$ & 2178 & 43.56 & 11.93 & 62 & 25 & 20.3 & 13.10 & 10.74 \\
\hline A & 4254 & 85.08 & 23.29 & 132 & 49 & 20.4 & 22.85 & 23.74 \\
\hline $\mathrm{CN}$ & 331 & 6.62 & 1.81 & 14 & 1 & 40.59 & 2.35 & 1.27 \\
\hline $\mathrm{CNE}$ & 190 & 3.88 & 1.04 & 8 & 0 & 54.1 & 1.48 & 0.60 \\
\hline $\mathrm{CE}$ & 123 & 2.80 & 0.67 & 7 & 0 & 61.03 & 0.93 & 0.42 \\
\hline CSE & 131 & 2.91 & 0.72 & 7 & 0 & 51.69 & 0.71 & 0.72 \\
\hline $\mathrm{CS}$ & 96 & 2.4 & 0.53 & 5 & 0 & 50.64 & 0.36 & 0.69 \\
\hline CSW & 225 & 4.79 & 1.23 & 10 & 0 & 52.44 & 0.69 & 1.78 \\
\hline $\mathrm{CW}$ & 343 & 6.86 & 1.88 & 17 & 2 & 40.27 & 1.44 & 2.32 \\
\hline $\mathrm{CNW}$ & 352 & 7.04 & 1.93 & 17 & 2 & 46.00 & 1.95 & 1.91 \\
\hline AN & 202 & 4.30 & 1.11 & 11 & 0 & 56.56 & 1.56 & 0.65 \\
\hline ANE & 161 & 3.35 & 0.88 & 12 & 0 & 59.47 & 1.33 & 0.43 \\
\hline $\mathrm{AE}$ & 171 & 3.56 & 0.94 & 10 & 0 & 57.88 & 1.31 & 0.56 \\
\hline ASE & 330 & 6.6 & 1.81 & 14 & 1 & 42.85 & 2.08 & 1.54 \\
\hline AS & 377 & 7.54 & 2.06 & 15 & 2 & 43.88 & 1.57 & 2.56 \\
\hline ASW & 674 & 13.48 & 3.69 & 24 & 6 & 30.17 & 2.34 & 5.05 \\
\hline AW & 498 & 9.96 & 2.73 & 23 & 3 & 41.52 & 2.00 & 3.46 \\
\hline ANW & 325 & 6.63 & 1.78 & 12 & 2 & 42.50 & 1.75 & 1.81 \\
\hline $\mathrm{U}$ & 794 & 4.26 & 4.35 & 29 & 8 & 33.09 & 6.81 & 1.88 \\
\hline Total & 18,262 & & & & & & & \\
\hline
\end{tabular}

Values in italics mean more common in this season
CE, CSE, CS, CSW, CW, CNW) and (iii) weak vorticity termed 'advective' or 'ADV' (N, NE, E, SE, S, SW, W).

Set 2 In this set, eight groups describe the directional component of circulation. For instance, the northerly direction group $[\mathrm{N}]$ includes $\mathrm{N}, \mathrm{CN}$ and $\mathrm{AN}$ days; the westerly direction groups include $\mathrm{W}, \mathrm{AW}$ and $\mathrm{CW}$; and so on. The northerly component $(<\mathrm{N}>)$ sums the days $\mathrm{N}, \mathrm{CN}, \mathrm{AN}, \mathrm{NE}, \mathrm{CNE}$, NW, CNW and ANW; the westerly component $(<\mathrm{W}>)$ counts W, CW, ASW, NW, ANW, CNW, SW, CSW and ASW; and so on.

Adding the number of pure $\mathrm{C}$ type days to the cyclonic hybrids yields 3974 days with cyclonic curvature or positive vorticity. CYC types represent $21 \%$ of all days, but this is greatly exceeded by the number of ANT days with negative vorticity (6992 or $38.3 \%$ ). The monthly pattern in the mean numbers of CYC and ANT days (Fig. 4) depicts an increase in vorticity in late spring and early summer, a reduction in August and a further rise in autumn. The rise in vorticity reflects the extension of influence of the two large high pressure areas in Asia: the subtropical high to the south in summer and the Siberian high in the northeast in winter. On the other hand, increases in cyclonicity in autumn accompany the renewal of enhanced westerly flow at this time of year.

Considerable variation exists in the occurrence of directional groups; however, over the longer term, the most important flow is westerly. On the whole groups of easterly types are least frequent, yet its importance is significant in mid-summer (Fig. 5) during which it can exceed both northerly and southerly components. This is a consequence of the large-scale pressure fall to the east, particularly the development of the Tibetan lowpressure system. Monthly frequencies of all directions follow distinct seasonal patterns with southerly and westerly groups showing a strong association with the winter half of the year. 


\section{Comparison to JCBI record}

Differences between the mid-latitude circulation catalogues for this continental area to the well-established JCBI record can be examined. In order to do so, the same period (19612010 ) is summarised for the JCBI catalogue. The centre of the $\mathrm{JCBI}$ grid lies at $5^{\circ} \mathrm{W}$ and some at $60^{\circ}$ or $3700 \mathrm{~km}$ from the mid-point of the Russian grid. In the long term, differences in the importance of weather types should be a response to hemispheric-scale patterns of sea level pressure, that is the mean longitudinal positions of the main axes of troughs and ridges. Furthermore, given that mean surface pressure in the Northern Hemisphere is strongly influenced by the distribution of land and sea, then the main differences between the two catalogues should reflect their maritime or continental locations. Notwithstanding this, there is a similar pattern in the relative frequency of types between the two records. In the JCBI system, A is the most frequent type (21.4\%), followed by $\mathrm{C}(13.2 \%)$ and then $\mathrm{W}(10 \%)$ and SW $(9 \%)$. The greatest percentage difference of the numbers of individual types is the $U$ type which is 3 times more common in the south-west Russia area than the British Isles. U types in the Russian catalogue are most frequent in the summer months of May, June and July when slack pressure gradients are observed. This is similar (but not as extreme) as that reported by Jorba et al. (2004) for Mediterranean latitudes.

Applying the JC method to the south-west Russia area results in a more equal distribution of days across the 27 weather types. A way of quantifying this spread is to calculate the deviation in the total numbers of days classified under each weather type from the value if there were equal numbers of days in each of the 27 weather types (676 days) and then divide the sum of these deviations by 18,262 . This indicative value would therefore range from 0 , if there were equal numbers of days in each weather type, to 1.93 , if all days were classified in the same category. In this case, the value suggests marginally more clustering in the case of the JCBI record (0.84) than for JCSWR (0.76).

Gross circulation differences can be illustrated by the groupings of weather types. With respect to the vorticity groups, CYC and ANT, there are less cyclonic days (on average, 11 less per year) and more anticyclonic circulation types (on average, 11 more per year) in the JCSWR catalogue. This indicates the stronger control on circulation of the polar front directing travelling depressions in the British Isles area. Furthermore, patterns of cyclonicity differ during the year (Fig. 6) and, hence, the average timing of cyclonic rainfall will differ between locations.

Considerable differences can also be seen in the number of days within each directional group (Table 3 ). There are significantly greater amounts of days with the compared northerly and easterly components in Russia and southerly and westerly components in the British Isles $\left(\chi^{2}=249.8, p<0.001\right)$. These differences occur in all seasons. Northerly and easterly flow direction is a response to relatively frequent location of anticyclonic centres over north-west Russia and Scandinavia (Fig. 7), whereas to the north-west of the British Isles, there is a far greater likelihood of troughs directing SW and W flow.

\section{Precipitation in the study area}

\subsection{General characteristics}

Rainfall data were obtained from the 518 station datasets of Bulygina and Razuvaev (2012) made available by the Carbon Dioxide Information Analysis Center (CDIAC 2014). Thirty stations were extracted from within the classified grid (appendix 2). There is a significant latitudinal decrease in annual precipitation amounts from north to south within this sample window $(r=0.648, p<0.05)$ and also a significant correlation with altitude $(r=0.490, p<0.05)$. These geographical relationships are stronger in the summer than in the winter months. Variability of rainfall, as measured by the coefficient of variation of monthly rainfall amounts, also significantly increases with decreasing altitude and latitude. Examination of the mean rainfall per event suggesting a relatively small number of convective storms explains the peak in rainfall amounts in summer months (Fig. 8). For instance, at Kushnarenkovo $\left(55.13^{\circ} \mathrm{N}, 55.35^{\circ} \mathrm{E}\right)$, a simple ratio of the 'number of dry days $(<0.2 \mathrm{~mm})$ ' to the 'number of days with

Table 2 Total number of days, annual mean and percentage of the groupings of advective types

\begin{tabular}{|c|c|c|c|c|c|c|c|c|}
\hline & $\begin{array}{l}\text { Northerly } \\
\text { direction }[\mathrm{N}]\end{array}$ & $\begin{array}{l}\text { Easterly } \\
\text { direction [E] }\end{array}$ & $\begin{array}{l}\text { Southerly } \\
\text { direction }[\mathrm{S}]\end{array}$ & $\begin{array}{l}\text { Westerly } \\
\text { direction [W] }\end{array}$ & $\begin{array}{l}\text { Northerly } \\
\text { component }<\mathrm{N}>\end{array}$ & $\begin{array}{l}\text { Easterly } \\
\text { component }<\text { E }>\end{array}$ & $\begin{array}{l}\text { Southerly } \\
\text { component }<\mathrm{S}>\end{array}$ & $\begin{array}{l}\text { Westerly } \\
\text { component }<\text { W }>\end{array}$ \\
\hline Total & 1240 & 666 & 1131 & 2173 & 3955 & 2536 & 4487 & 6190 \\
\hline Mean & 24.80 & 13.32 & 22.62 & 43.46 & 79.10 & 50.72 & 89.74 & 123.80 \\
\hline$\%$ & 6.79 & 3.65 & 6.19 & 11.90 & 21.66 & 13.89 & 24.57 & 33.90 \\
\hline Max & 12 & 3 & 9 & 24 & 51 & 30 & 53 & 77 \\
\hline Min & 39 & 30 & 34 & 69 & 122 & 76 & 117 & 154 \\
\hline $\mathrm{CV}$ & 25.57 & 37.57 & 27.63 & 22.89 & 17.69 & 20.85 & 13.53 & 14.14 \\
\hline
\end{tabular}




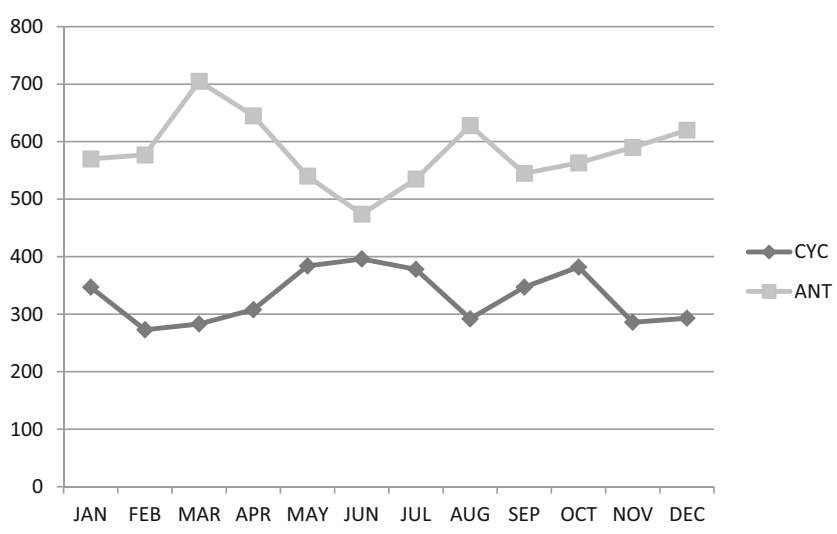

Fig. 4 Monthly regimes of cyclonic $(C Y C)$ and anticyclonic (ANT) groupings

falls over $10 \mathrm{~mm}$ ' yields a value of 92 in mid-winter in January (739:8) but 11 in July (944:86).

In order to examine the spatial and temporal variability of rainfall across the area, groups of covarying locations can be identified. A multivariate technique, used for instance by Romero et al. (1999), can determine rainfall affinity areas (RAAs) by applying principal component analysis to the full dataset and then grouping locations with similar component scores using the $k$-means clustering algorithm. Application of this regionalisation technique results in four distinct RAAs which have marginally different group memberships in summer and winter months (Fig. 9). The rainfall regime of at least one key representative station within each RAA can be used to illustrate the findings of this research. The general rainfall regime for each of these stations is listed in Table 4. Groups 1, 2 and 3 display regimes with a peak in totals in June and July and are differentiated by the influence of the latitude and altitudinal control (the mean altitude of stations in each group is 144, 105 and $452 \mathrm{~m}$, respectively). The southerly group 4 is much drier with a reduced summer peak and a second relatively wet spell in late autumn.

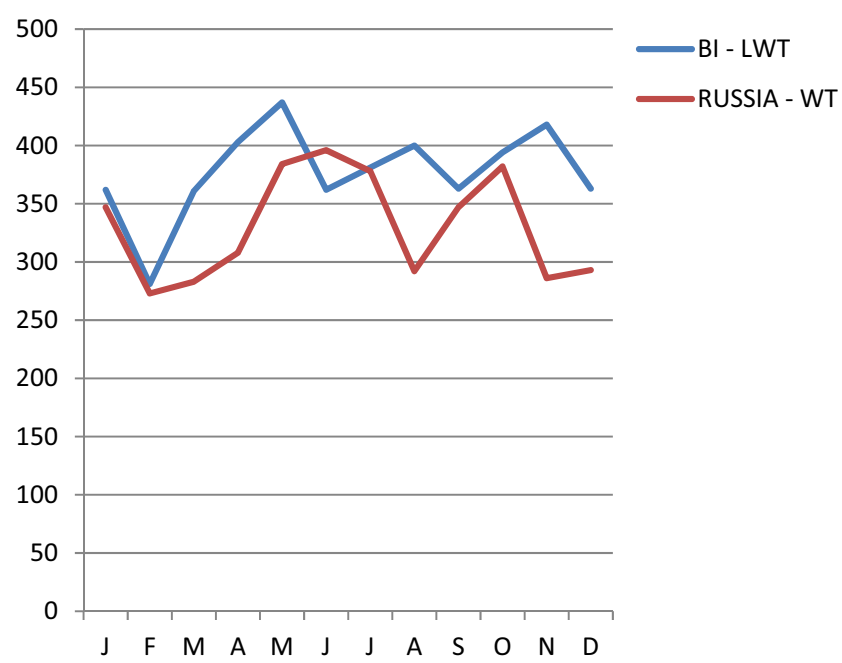

Fig. 6 Total monthly cyclonic (CYC) days

\subsection{Daily rainfall distribution}

Establishing a statistical model to capture the behaviour of precipitation systems has long been a topic of interest (Hanson and Vogel 2008), but due to the complex nature of precipitation processes, these models have been selected by goodness-of-fit criteria rather than being derived from knowledge of the underlying physical processes (Duan et al. 1998). There are many probability distributions that have been seen to successfully parameterise rainfall distributions, and the critical component is that they are flexible enough to represent a variety of rainfall regimes. The gamma distribution is often used to model the distribution of daily rainfall amounts as it suits the distribution of daily rainfall and accommodates the lower limit of zero which constrains rainfall values (Wilks 2006). Other distributions include the Weibull distribution (e.g. Boulanger et al. 2007), the log-normal (e.g. Shoji and Kitaura 2006) and the mixed exponential distribution (e.g. Wilks 1999). Studies that have compared the suitability of two or more different distributions such as Boulanger et al.
Fig. 5 Monthly mean for directional component groups

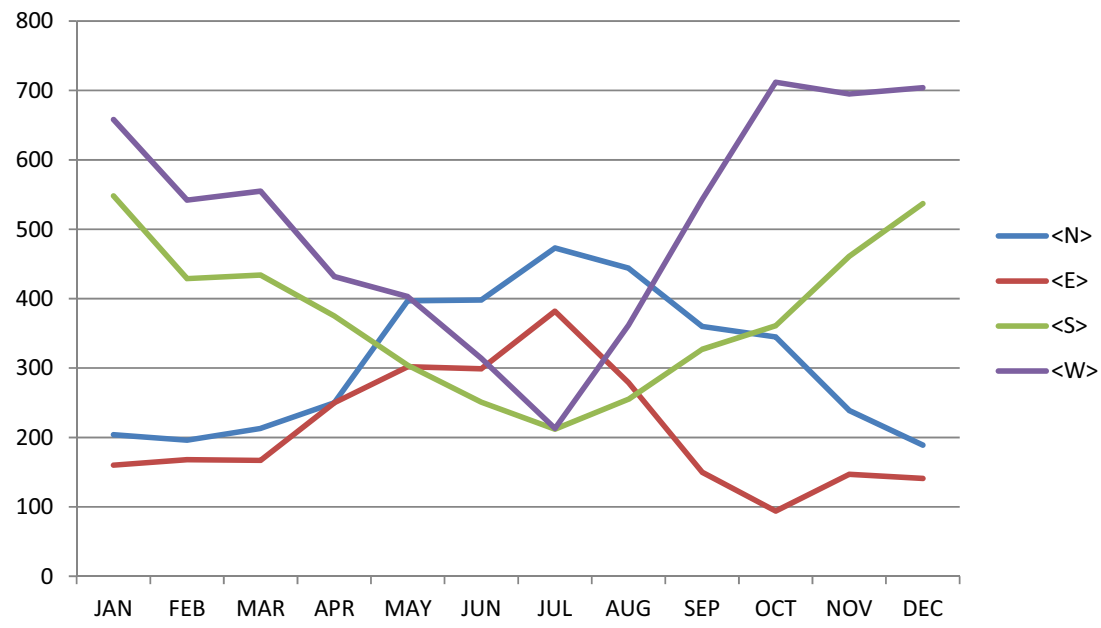


Table 3 Number of days within each direction group for JCBI and JCSWR Russia 1961-2010

\begin{tabular}{lllll}
\hline & JCBI & JCSWR & $\chi^{2}$ & $p$ \\
\hline$[\mathrm{N}]$ & 1071 & 1238 & 160.9 & $<0.001$ \\
{$[\mathrm{E}]$} & 558 & 661 & & \\
{$[\mathrm{~S}]$} & 1769 & 1126 & & \\
{$[\mathrm{~W}]$} & 2864 & 2173 & & $<0.001$ \\
$<\mathrm{N}>$ & 3311 & 3708 & 249.7 & \\
$<\mathrm{E}>$ & 1939 & 2539 & & \\
$<\mathrm{S}>$ & 5025 & 4494 & & \\
$<\mathrm{W}>$ & 7187 & 5136 & & \\
\hline
\end{tabular}

(2007) have found that no single distribution consistently suits all regions, seasons and climates better than others. In this study, daily station precipitation distribution was fitted to a number of probability distributions. Although the differences between performances were not considerable, the Weibull distribution repeatedly provided the best-fit probability distribution for rainfall.

\subsection{Rainfall and weather type}

Should a significant synoptic control on rainfall be established, then consideration of the prevailing weather type should improve the accuracy of modelled rainfall over the simulation of a rainfall regime based on features of a probability distribution alone. The synoptic classification was, therefore, first examined to determine if consistent stable relationships between weather types and precipitation could be identified. The fundamental assessment of how dry or how wet a weather type is summarised by the following simple relative performance index (RPI) which can be calculated for each weather type at each location:

$\mathrm{RPI}=\frac{\mathrm{WTRF}}{\mathrm{RF}}$

In this equation, RPI is the relative performance index of each weather type, WTRF refers to the mean rainfall for the weather type, and RF refers to the mean rainfall at that location under all the weather types. The resulting value can be used to determine if a type is wet $(<1.00)$, dry $(>1.00)$ or non-distinct (1.00). The RPI values are listed in Table 5. Positive (wet) values are shown in italics. As expected, negative vorticity types and groups (A, ANT), as a result of their atmospheric stability, result in dry conditions whereas CYC days are universally wet. The relationship between directional types and rainfall is less easy to interpret and depends on the location of the station considered; nevertheless, rainfall amounts in the southern half of the study area are more associated with northerly and easterly flow whereas westerly types are important drivers of precipitation in the north. In the summer months, actual rainfall amounts show a high degree of variability under
Fig. 7 Synoptic pattern of 2 October 2010, leading to NE flow in the study area

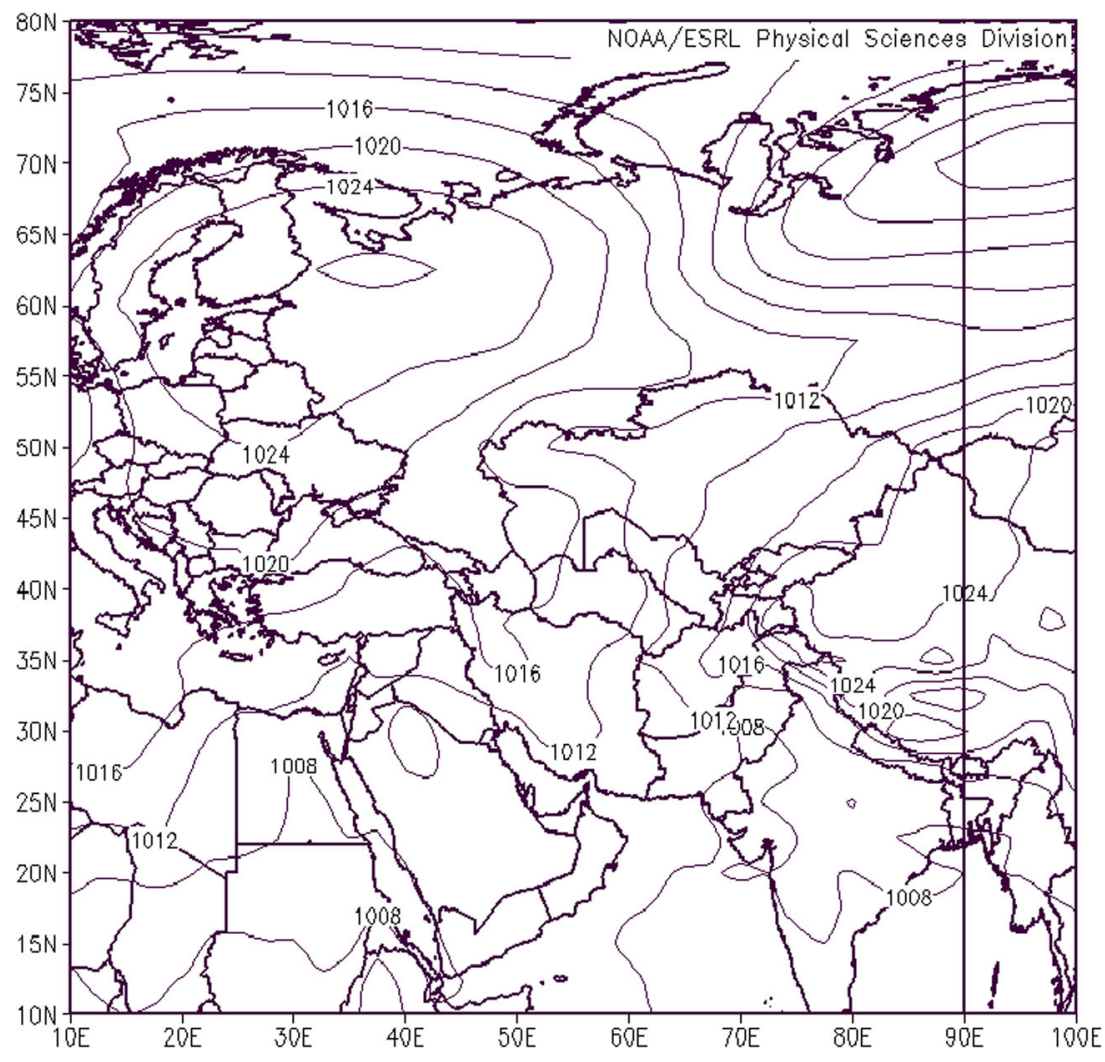


Fig. 8 Mean daily rainfall (mm) by month for representative stations in each RAA

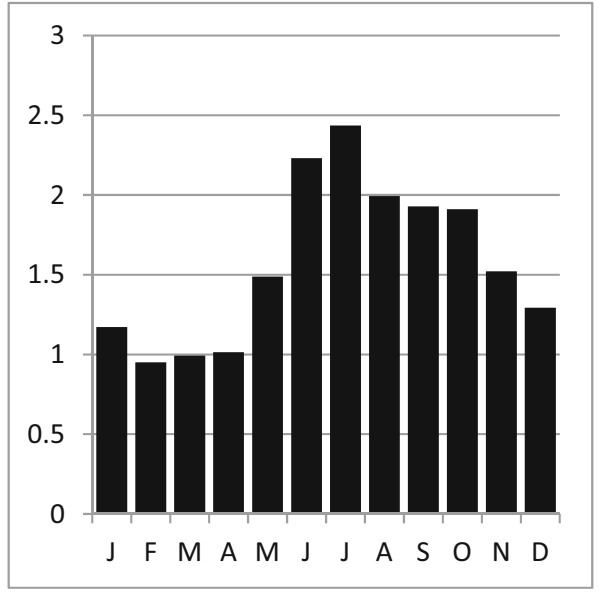

Kumeny $\left(58.10^{\circ} \mathrm{N}, 49.92^{\circ} \mathrm{E}\right)(\mathrm{RAA} 1)$

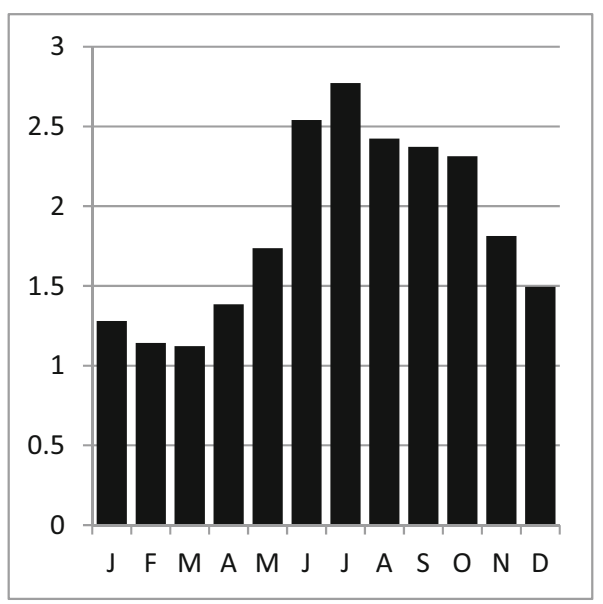

Tukan $\left(53.87^{\circ} N, 57.42^{\circ} E\right)(R A A 3)$

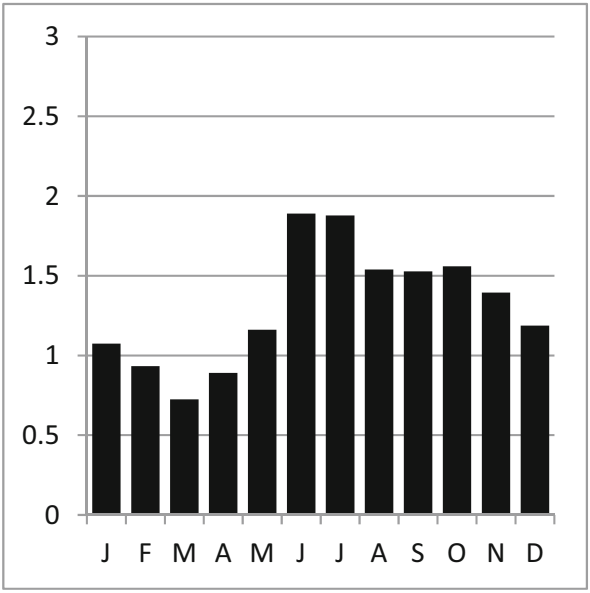

Kushnarenkovo $\left(55.13^{\circ} \mathrm{N}, 55.35^{\circ} \mathrm{E}\right)(\mathrm{RAA} 2)$

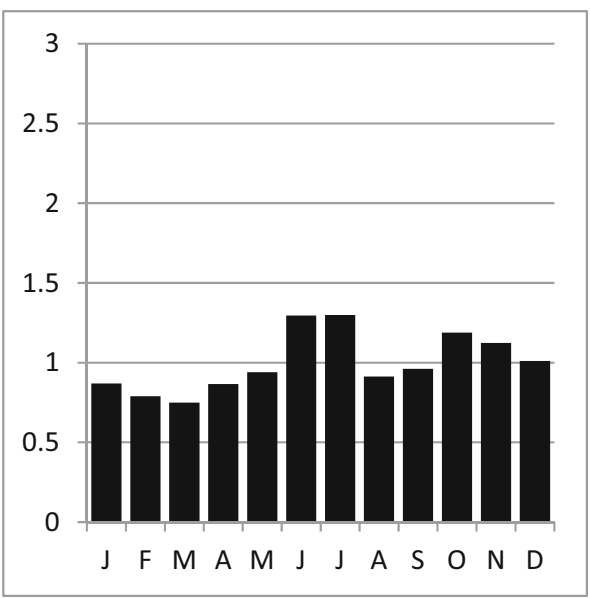

Orenburg $\left(51.68^{\circ} \mathrm{N}, 55.10^{\circ} \mathrm{E}\right)(\mathrm{RAA} 4)$ each weather type. This is consistent with findings by other authors (e.g. El-Kadi and Smithson 1996) who identify the stronger synoptic control on rainfall amounts in winter due to the high variability in the spatial nature and the depth of rainfall from summer convective mechanisms.

To determine if there is effective statistical differentiation of rainfall amounts by weather types, a non-parametric test of
Fig. 9 Regionalisation of meteorological stations in the study area for winter half of the year

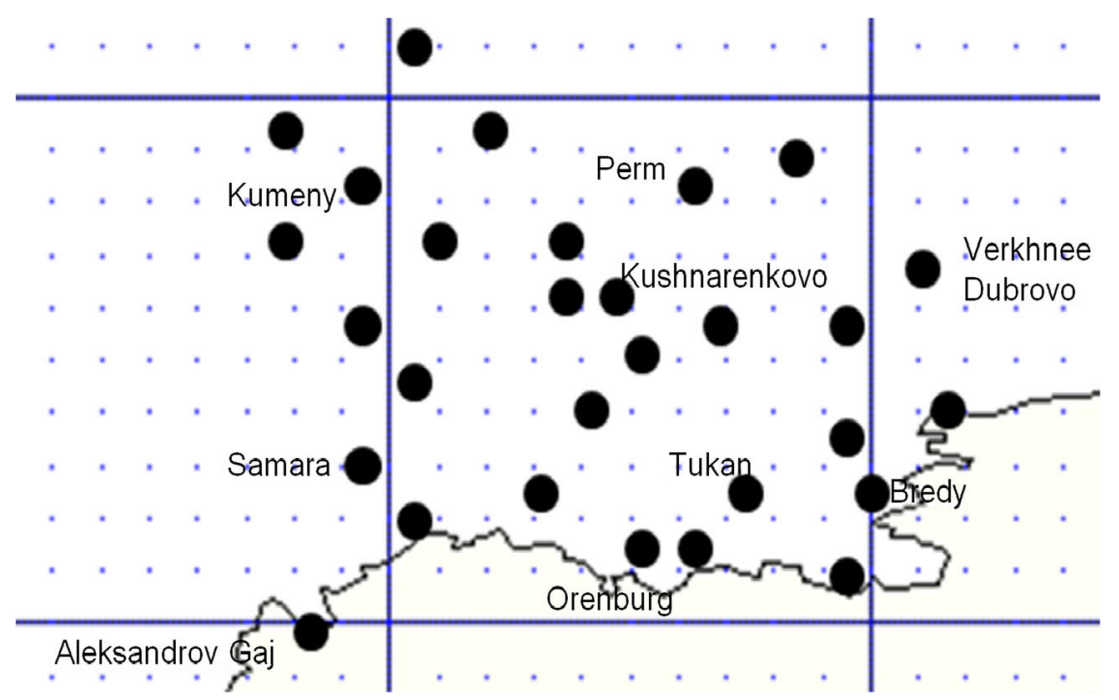


difference was applied to daily rainfall regimes under each of the most frequent types. Kruskal-Wallis one-way analysis of variance determines the probability that daily rainfall recorded under each of the main weather types originates from the same distribution. The test identifies a significant difference between at least two of the groups at each station for all years, summer and winter periods at $p<0.001$. Further analysis (Mann-Whitney $U$ test) using pairs of weather types for all groups indicates a statistically significant weather type-based distinction between rainfall regimes. Only the southerly types (SW, SE and S) in group 4 and $\mathrm{SW}$ and $\mathrm{W}$ in group 2 stations do not exhibit clear differences at the 0.05 level.

\subsection{Modelling the association of circulation type and rainfall}

The strength of the association between weather types and precipitation behaviour can be tested using a simple model. In order to do this, the whole dataset was divided into a calibration set, in which relationships between rainfall and weather types were established, and a validation set in which the rainfall was modelled using the relationships that exist in the calibration set. The success of this method depends on a consistent relationship between precipitation and the weather type - a situation termed 'stationarity'. In this study, the 18 , 262 days are first divided into two subsets of data: the summer months (April to September, 9150 days) and the other the rest of the winter months (October to March, 9112 days). From each subset, only those days with the eight most recurring weather types in each season are retained (summer $63.6 \%$ or 5821 days; winter $73 \%$ or 6665 days). This is done to reduce the effect of the very infrequent hybrid types in the modelling process. Finally, the resulting two sets are further divided into calibration $(90 \%)$ and validation $(10 \%)$ sets. There is some discussion in the literature (e.g. Mourad et al. 2005) on the optimum size of calibration and validation sets for this type of model. Clearly, better calibration can be achieved when a large number of cases can be presented for model calibration yet, at the same time, better validation results will likewise be obtained using a large validation set. In this model, a relatively small validation set of $10 \%$ of days was chosen for both the summer and winter validations. Days within this set were determined using random numbers.

After calibration, a daily rainfall prediction for the validation set was made using the following: (a) a distribution-based model in which a value for each day was drawn at random from a Weibull frequency distribution with scale and shape parameters based on the characteristics of the calibration data in each season and (b) a weather type model in which the mean value for each weather type was calculated from the calibration set in each season. The performance of each model is then determined by calculating the mean daily modelled rainfall for each key station for each season over the length

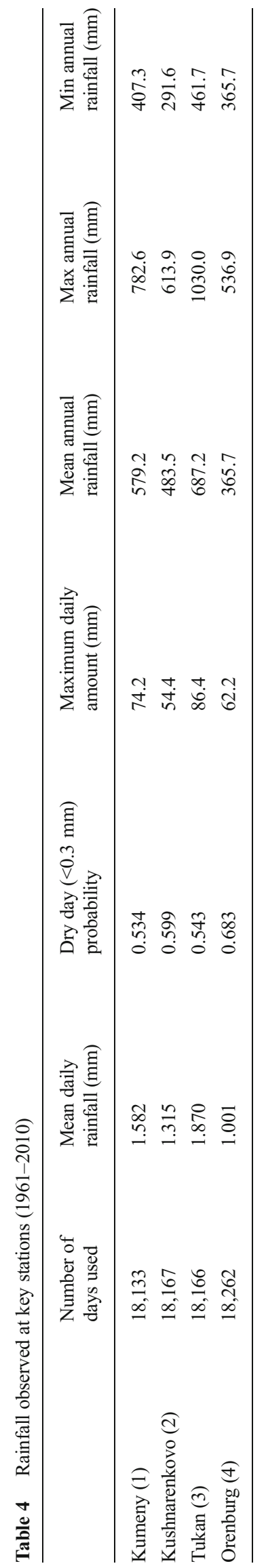


Table 5 Relative performance index of daily rainfall (all months) for pure types

\begin{tabular}{lllllllllllll}
\hline & $\mathrm{A}$ & $\mathrm{C}$ & $\mathrm{N}$ & $\mathrm{NE}$ & $\mathrm{E}$ & $\mathrm{SE}$ & $\mathrm{S}$ & $\mathrm{SW}$ & $\mathrm{W}$ & $\mathrm{NW}$ & ANT & CYC \\
\hline Kumeny & 0.456 & 1.518 & 0.327 & 0.189 & 0.303 & 0.961 & 1.856 & 2.19 & 1.280 & 0.733 & 0.638 & 1.342 \\
Kushnarenkovo & 0.458 & 2.258 & 0.830 & 0.718 & 0.632 & 0.951 & 0.771 & 1.070 & 1.026 & 0.874 & 0.697 & 1.654 \\
Tukan & 0.336 & 1.945 & 1.524 & 1.391 & 1.018 & 0.713 & 0.400 & 0.713 & 1.257 & 1.699 & 0.409 & 1.934 \\
Orenburg & 0.456 & 2.219 & 2.11 & 1.319 & 2.492 & 1.605 & 0.708 & 0.737 & 0.637 & 0.568 & 0.515 & 1.975 \\
\hline
\end{tabular}

Positive RPI values (relatively wet types) are presented in italics

of the validation set and then calculating the percentage error (Table 6).

Table 6 shows that in the winter months, although the modelled value performs reasonably well and the error in the mean daily amount is generally less than $10 \%$, the modelled data using the rather crude measure of the mean of each JC type performs better. This indicates the strong stability in the relationship between circulation type and rainfall amounts. As expected, the use of calibration set mean values fails to capture the variability in the daily data and, as a consequence, the variability of the rainfall is poorly represented and much better represented using the distribution that does not take into account the circulation. The prediction of summer rainfall is considerably less accurate, suggesting a lack of coherent response in rainfall totals with weather type. For instance, at Tukan $\left(53.87^{\circ} \mathrm{N}, 57.42^{\circ} \mathrm{E}\right)$, the weather type model has a $15.77 \%$ underprediction and the frequency model overpredicts by $20.7 \%$ in the summer.

\section{Conclusion}

This study demonstrates that the JC weather typing method can successfully be applied to a mid-latitude region with a high degree of continentality. It demonstrates the key modes of atmospheric circulation and can be used to identify a clear association with precipitation behaviour despite the lack of apparent direction-based moisture contrasts in advected air.
A catalogue of sea level pressure patterns, and hence weather type, was created using the Jenkinson and Collison method for the 1961-2010 period for an area in south-west Russia. The continental location of the study area catalogue contrasts with other synoptic catalogues, yet Jones et al. (2013) have suggested that the JC method should be applicable to any mid-to-high-latitude region. In this case, there is not only a typical mid-latitude importance of A (23.3\%) and C (11.9\%) pure types but also a diversity of other weather types. There are relatively few hybrid types occurring in any one year. If types are grouped, the number of days with anticyclonic curvature $(38.3 \%)$ greatly exceeds that with cyclonic curvature (21\%); however, the difference is less marked in early summer.

The number of undetermined ( $4 \%$ ) is less than that found in lower latitudes, but they are more frequent, particularly in the summer months, than at the western continental margin (i.e. the British Isles). Main differences are largely a consequence of the difference in location. There is a significant importance of easterlies in summer; for instance, in July, the total easterly component days is 126 in the British Isles against 382 for the Russian area. The resulting pattern shows some influence by well-known circulation features near this area and also the importance of the westerly flow associated with the polar front.

The utility of the catalogue in explaining surface meteorology is explored with respect to daily rainfall amounts. A clear relationship can be found between circulation pattern and

Table 6 Performance of simple models of rainfall

\begin{tabular}{|c|c|c|c|c|c|c|c|c|}
\hline & $\begin{array}{l}\text { Observed } \\
\text { mean }(\mathrm{mm})\end{array}$ & $\mathrm{SD}(\mathrm{mm})$ & $\begin{array}{l}\text { Frequency model } \\
\text { mean }(\mathrm{mm})\end{array}$ & $\mathrm{SD}(\mathrm{mm})$ & $\%$ error & $\begin{array}{l}\text { Weather type } \\
\text { model mean }(\mathrm{mm})\end{array}$ & $\mathrm{SD}(\mathrm{mm})$ & $\%$ error \\
\hline \multicolumn{9}{|l|}{ Kumeny } \\
\hline Perma & 1.5691 & 2.56 & 1.5339 & 2.02 & -2.24 & 1.5691 & 0.84 & 0.00 \\
\hline Verhnee Dubrovo & 0.8293 & 1.81 & 0.8898 & 1.46 & +7.29 & 0.8293 & 0.61 & 0.00 \\
\hline Samara & 1.0542 & 2.23 & 1.1260 & 1.81 & +6.81 & 1.0537 & 0.91 & -0.05 \\
\hline Kushnarenkovo & 1.1341 & 2.21 & 1.1873 & 1.87 & +4.69 & 1.1355 & 0.62 & +0.12 \\
\hline Tukan & 1.4480 & 2.80 & 1.3767 & 2.08 & -4.92 & 1.4436 & 0.92 & -0.30 \\
\hline Alexsandrov Gaj & 0.7226 & 1.89 & 0.9447 & 1.58 & +30.74 & 0.7212 & 0.61 & -0.19 \\
\hline Bredy & 0.6443 & 1.86 & 0.6113 & 1.22 & -5.12 & 0.6445 & 0.48 & +0.03 \\
\hline Orenburg & 0.8303 & 2.19 & 0.7372 & 1.42 & -11.2 & 0.8302 & 0.73 & -0.01 \\
\hline
\end{tabular}


rainfall amount, and a significance test proves that different regimes exist under each type. In order to test these datasets, rainfall amounts can be tested using a small validation dataset with the relationship between weather type and rainfall being established with a much larger calibration set. Although methodologically unnecessary, the utility of the weather type model was repeatedly tested using different randomly selected calibration and validation sets and repeatedly produced accurate prediction which improved that from a frequency distribution model, but this was only observed in the winter. This is common with other authors (e.g. El-Kadi and Smithson 1996) who have found that the use of synoptic climatologically- precipitation relationship is much stronger in winter. Inevitably, this is due to the significant amount of rainfall that derives from convective activity which has less of a coherent synoptic signal.

\section{Appendix 1}

The equations used to determine the airflow indices needed to generate a JC type for each day are as follows (the numbers in bold refer to the grid point reference in Fig. 3)

$$
\begin{aligned}
& \text { Westerly flow }(W)=0.5(\mathbf{1 2}+\mathbf{1 3})-0.5(\mathbf{4}+\mathbf{5}) \\
& \text { Southerly flow }(S)=1.74[(0.25(\mathbf{5}+2.0 \times \mathbf{9}+\mathbf{1 3})-(0.25(\mathbf{4}+2.0 \times \mathbf{8}+\mathbf{1 2})] \\
& \text { Resultant flow }(F)=\left(S^{2}+W^{2}\right)^{0.5} \\
& \text { Westerly shear velocity }(Z W)=1.07[0.5(\mathbf{1 5}+\mathbf{1 6})-0.5(\mathbf{8}+\mathbf{9})]-0.95[0.5(\mathbf{8}+\mathbf{9})-0.5(\mathbf{1}+\mathbf{2})] \\
& \text { Southerly shear velocity }(Z S)=1.52[0.25(\mathbf{6}+2.0 \times \mathbf{1 0}+\mathbf{1 4})-0.25(\mathbf{5}+2.0 \times \mathbf{9}+\mathbf{1 3})-0.25(\mathbf{4}+2.0 \times \mathbf{8}+\mathbf{1 2}) \\
& \qquad \begin{array}{r}
+0.25(\mathbf{3}+2.0 \times \mathbf{7}+\mathbf{1 1})] \text { Total shear velocity }=Z=Z W+Z S
\end{array}
\end{aligned}
$$

The flow units are geostrophic (each is equivalent to 1.2 knots) expressed as hectopascals $(\mathrm{hPa})$ per $10^{\circ}$ latitude at $55^{\circ} \mathrm{N}$. The geostrophic vorticity units are expressed as hPa per $10^{\circ}$ latitude also at $55^{\circ} \mathrm{N} ; 100$ units are equivalent to $0.55 \times 10^{-4}$ which is 0.46 times the Coriolis parameter at $55^{\circ}$ $\mathrm{N}$. The constants in the equations account for the relative differences between grid point spacing in the east-west and northsouth direction.

The equations use a number of coefficients, calculated by Jenkinson and Collison (1977) to take into account the different relative grid spacing at different latitudes. In order to be applied at different latitudes, the coefficients are explained below for latitude $55^{\circ}(\psi)$

$S 1.74$ is $1 / \cos (\psi) Z W 1.07$ and 0.95 are $\sin (\psi) / \sin \left((\psi)-5^{\circ}\right)$ and $\sin (\psi) / \sin \left((\psi)+5^{\circ}\right) Z S 1.52$ is $0.5\left(\cos ((\psi))^{2}\right)$

Jenkinson and Collison (1977) used the following rules to determine the appropriate LWT: (i) The direction of flow is $\tan (W / S)$. Add $180^{\circ}$ if $W$ is positive. The appropriate direction is calculated on an 8-point compass allowing $45^{\circ}$ per sector. Thus, $W$ occurs between $247.5^{\circ}$ and $292.5^{\circ}$

(ii) If $|Z|$ is less than $F$, then the flow is essentially straight and corresponds to a Lamb pure directional type.

(iii) If $|Z|$ is greater than $2 F$, then the pattern is strongly cyclonic $(Z>0)$ or anticyclonic $(Z<0)$. This corresponds to Lamb's pure cyclonic and anticyclonic type.

(iv) If $|\mathrm{Z}|$ lies between $F$ and $2 F$, then the flow is partly (anti) cyclonic and this corresponds to one of Lamb's synoptic/direction hybrid types, e.g. $\mathrm{AE}$.

(v) If $F$ is less than 6 and $|\mathrm{Z}|$ is less than 6 , there is light indeterminate flow corresponding to Lamb's unclassified type $U$. The choice of 6 is dependent on the grid spacing and would need tuning if used with a finer grid resolution. 


\section{Appendix 2}

Table 7 Details of 30 meteorological stations examined in this study

\begin{tabular}{|c|c|c|c|c|c|c|c|}
\hline $\begin{array}{l}\text { Station } \\
\text { number }\end{array}$ & Station name & Latitude & Longitude & Altitude (m) & Opened & $\begin{array}{l}\text { PAA } \\
\text { (winter) }\end{array}$ & $\begin{array}{l}\text { PAA } \\
\text { (summer) }\end{array}$ \\
\hline 23904 & Kojgorodok & 60.45 & 50.97 & 124 & 1959 & 1 & 1 \\
\hline 27083 & Oparino & 59.85 & 48.28 & 179 & 1940 & 1 & 1 \\
\hline 27296 & Kumeny & 58.10 & 49.92 & 175 & 1940 & 1 & 1 \\
\hline 27385 & Jaransk & 57.37 & 47.92 & 103 & 1940 & 1 & 2 \\
\hline 27595 & Kazanâ€тм & 55.73 & 49.20 & 116 & 1812 & 1 & 3 \\
\hline 27995 & Samara (Bezencuk) & 52.98 & 49.43 & 45 & 1904 & 4 & 2 \\
\hline 28009 & Kirs & 59.37 & 52.22 & 168 & 1940 & 1 & 1 \\
\hline 28138 & Biser & 58.52 & 58.85 & 463 & 1888 & 3 & 3 \\
\hline 28224 & Permâ€ $€^{\mathrm{TM}}$ & 58.02 & 56.30 & 171 & 1866 & 2 & 2 \\
\hline 28312 & Debessy & 57.63 & 53.82 & 187 & 1940 & 2 & 2 \\
\hline 28401 & Kila & 56.90 & 51.07 & 143 & 1940 & 2 & 2 \\
\hline 28418 & Sarapul & 56.47 & 53.73 & 135 & 1940 & 1 & 2 \\
\hline 28419 & Janaul & 56.27 & 54.90 & 98 & 1940 & 2 & 2 \\
\hline 28445 & Verhnee Dubroo & 56.73 & 61.07 & 287 & 1959 & 2 & 3 \\
\hline 28537 & Duvan & 55.70 & 57.90 & 337 & 1940 & 2 & 2 \\
\hline 28624 & Kushnarenkovo & 55.13 & 55.35 & 98 & 1959 & 2 & 2 \\
\hline 28630 & Zlatoust & 55.17 & 59.67 & 532 & 1936 & 3 & 3 \\
\hline 28704 & Culpanovo & 54.50 & 50.42 & 76 & 1929 & 2 & 2 \\
\hline 28719 & Aksakovo & 54.03 & 54.18 & 357 & 1940 & 3 & 2 \\
\hline 28748 & Troizk & 54.08 & 61.62 & 192 & 1940 & 4 & 4 \\
\hline 28823 & Tukan & 53.87 & 57.42 & 551 & 1959 & 3 & 3 \\
\hline 28833 & Verhneuralâ€ $€^{\mathrm{TM}_{\mathrm{Sk}}}$ & 53.88 & 59.20 & 401 & 1903 & 4 & 4 \\
\hline 34391 & Aleksandrov Gaj & 50.15 & 48.55 & 23 & 1929 & 4 & 4 \\
\hline 35007 & Pereljub & 51.87 & 50.33 & 72 & 1933 & 4 & 4 \\
\hline 35011 & Sorocinsk & 52.43 & 53.13 & 122 & 1934 & 4 & 4 \\
\hline 35026 & Zilair & 52.22 & 57.40 & 522 & 1940 & 4 & 3 \\
\hline 35041 & Bredy & 52.43 & 60.35 & 309 & 1940 & 4 & 4 \\
\hline 35121 & Orenburg & 51.68 & 55.10 & 115 & 1843 & 4 & 4 \\
\hline 35127 & Ak-Bulak & 51.02 & 55.63 & 143 & 1927 & 4 & 4 \\
\hline 35233 & Dombarovskij & 50.75 & 59.55 & 277 & 1937 & 4 & 4 \\
\hline
\end{tabular}

Open Access This article is distributed under the terms of the Creative Commons Attribution 4.0 International License (http:// creativecommons.org/licenses/by/4.0/), which permits unrestricted use, distribution, and reproduction in any medium, provided you give appropriate credit to the original author(s) and the source, provide a link to the Creative Commons license, and indicate if changes were made.

\section{References}

Alijani B, Harman JR (1985) Synoptic climatology of precipitation in Iran. Ann Assoc Am Geogr 75:404-416

Barry RG, Chorley RJ (2009) Atmosphere, weather and climate. Routledge 
Boulanger JP, Martinez F, Penalba O, Segura EC (2007) Neural network based daily precipitation generator (NNGEN-P). Clim Dyn 28:307-324

Buishand TA, Brandsma T (1997) Comparison of circulation classification schemes for predicting temperature and precipitation in the Netherlands. Int J Climatol 17:875-889

Bulygina ON, Razuvaev VN (2012) Daily temperature and precipitation data for 518 Russian meteorological stations. Carbon Dioxide Information Analysis Center, Oak Ridge National Laboratory, U.S. Department of Energy, Oak Ridge, Tennessee. doi: 10.3334/ CDIAC/cli.100

Carbon Dioxide Information Analysis Center (CDIAC) (2014) http:// cdiac.ornl.gov/

Chen D (2000) A monthly circulation climatology for Sweden and its application to a winter temperature case study. Int J Climatol 20: 1067-1076

Duan J, Selker J, Grant GE (1998) Evaluation of probability density functions in precipitation models for the Pacific Northwest. J Am Water Resour Assoc 34:617-628

El-Kadi AK, Smithson PA (1996) An automated classification of pressure patterns over the British Isles. Trans Inst Br Geogr 16:141-156

Espinoza PS, Ruiz OM, Vide FJM (2014) Variabilidad y tendencias climáticas en Chile central en el período 1950-2010 mediante la determinación de los tipos sinópticos de Jenkinson y Collison. Boletín de la Asociación de Geógrafos Españoles 64:227-247

Fitzharris BB, Bakkehøi S (1986) A synoptic climatology of major avalanche winters in Norway. J Climatol 6:431-446

Grimalt $\mathrm{M}$, Tomàs $\mathrm{M}$, Alomar $\mathrm{G}$, Martin-Vide $\mathrm{J}$, Moreno-García MDC (2013) Determination of the Jenkinson and Collison's weather types for the western Mediterranean basin over the 1948-2009 period. Temporal analysis. Atmosfera 26:75-94

Hanson LS, Vogel R (2008) The probability distribution of daily rainfall in the United States. In Proc. World Environ Water Resources Congress, -10

Jahanbakhsh S, Zolfaghari H (2002) Synoptic patterns investigation of daily precipitations over the west of Iran. Geographic Res J, 63-64

Jenkinson AF, Collison FP (1977) An initial climatology of gales over the North Sea. Synoptic Climatol Branch Memorandum 62:18

Jones PD, Hulme M, Briffa KR (1993) A comparison of Lamb circulation types with an objective classification scheme. Int J Climatol 18:655663

Jones PD, Harpham C, Briffa KR (2013) Lamb weather types derived from reanalysis products. Int J Climatol 33:1129-1139
Jorba O, Pérez C, Rocadenbosch F, Baldasano J (2004) Cluster analysis of 4-day back trajectories arriving in the Barcelona area, Spain, from 1997 to 2002. J Appl Meteorol 43:887-901

Kalnay E, Kanamitsu M, Kistler R, Collins W, Deaven D, Gandin L, Joseph D (1996) The NCEP/NCAR 40-year reanalysis project. Bull Am Meteorol Soc 77:437-471

Kidson JW (1994) Relationship of New Zealand daily and monthly weather patterns to synoptic weather types. Int J Climatol 14:723737

Lamb HH (1972) British Isles weather types and a register of the daily sequence of circulation patterns 1861-1971. Her Majesty's Stationery Office

Mourad M, Bertrand-Krajewski JL, Chebbo G (2005) Calibration and validation of multiple regression models for stormwater quality prediction: data partitioning, effect of dataset size and characteristics. Water Sci Technol 52:45-52

Petrone RM, Rouse WR (2000) Synoptic controls on the surface energy and water budgets in sub-arctic regions of Canada. Int J Climatol 20: $1149-1165$

Post P, Truija V, Tuulik J (2002) Circulation weather types and their influence on temperature and precipitation in Estonia. Boreal Environ Res 7:281-289

Romero R, Sumner G, Ramis C, Genovés A (1999) A classification of the atmospheric circulation patterns producing significant daily rainfall in the Spanish Mediterranean area. Int J Climatol 19:765-785

Shoji T, Kitaura H (2006) Statistical and geostatistical analysis of rainfall in central Japan. Comput Geosci 32:1007-1024

Spellman G (2000) The use of an index-based regression model for precipitation analysis on the Iberian Peninsula. Theor Appl Climatol 66:229-239

Spence C, Rausch J (2005) Autumn synoptic conditions and rainfall in the subarctic Canadian Shield of the Northwest Territories, Canada. Int J Climatol 25:1493-1506

Trigo RM, DaCamara CC (2000) Circulation weather types and their influence on the precipitation regime in Portugal. Int J Climatol 20:1559-1581

Wilks DS (1999) Interannual variability and extreme-value characteristics of several stochastic daily precipitation models. Agric For Meteorol 93:153-169

Wilks DS (2006) Statistical methods in the atmospheric sciences. International Geophysics Series 2nd edn. Academic Press, London

Yarnal B (1993) Synoptic climatology in environmental analysis: a primer. Belhaven, London 